\title{
Sodium selenite alters microtubule assembly and induces apoptosis in vitro and in vivo
}

\author{
Kejian Shi, Qian Jiang, Zhushi Li, Lei Shan, Feng Li, JiaJia An, Yang Yang and Caimin Xu*
}

\begin{abstract}
Background: Previous studies demonstrated that selenite induced cancer-cell apoptosis through multiple mechanisms; however, effects of selenite on microtubules in leukemic cells have not been demonstrated.

Methods: The toxic effect of selenite on leukemic HL60 cells was performed with cell counting kit 8. Selenite effects on cell cycle distribution and apoptosis induction were determined by flow cytometry. The contents of cyclin B1, Mcl-1, AlF, cytochrome C, insoluble and soluble tubulins were detected with western blotting. Microtubules were visualized with indirect immunofluorescence microscopy. The interaction between CDK1 and Mcl-1 was assessed with immunoprecipitation. Decreasing Mcl-1 and cyclin B1 expression were carried out through siRNA interference. The alterations of Mcl-1 and cyclin B1 in animal model were detected with either immunohistochemical staining or western blotting. In situ detection of apoptotic ratio was performed with TUNEL assay.

Results: Our current results showed that selenite inhibited the growth of HL60 cells and induced mitochondrial-related apoptosis. Furthermore, we found that microtubule assembly in HL60 cells was altered, those cells were arrested at G2/M phase, and Cyclin B1 was up-regulated and interacted with CDK1, which led to down-regulation of the anti-apoptotic protein Mcl-1. Finally, in vivo experiments confirmed the in vitro microtubule disruption effect and alterations in Cyclin B1 and Mcl-1 levels by selenite.
\end{abstract}

Conclusions: Taken together, the results from our study indicate that microtubules are novel targets of selenite in leukemic HL60 cells.

Keywords: Sodium selenite, Apoptosis, Microtubule, Cell cycle

\section{Introduction}

Microtubules have important roles in many cell behaviors such as cell division, organelle positioning, vesicular transport and cell-shape determination [1-3]. Previous studies have showed that microtubule dynamics are necessary for these functions in vivo [2,4-6]. Therefore, chemicals affecting microtubule dynamics often impact these functions in vivo. On that basis, many anti-tumor agents have been developed for their effects on microtubule dynamics and cell-cycle distribution [7-12].

Selenium (Se) is an essential trace element [13], and appropriate selenium intake is necessary for the body to synthesize selenoproteins. Some researchers have shown that selenite concentrations that are within the nutritional

\footnotetext{
* Correspondence: caiminxu@yahoo.com.cn

State Key Laboratory of Medical Molecular Biology, Department of Biochemistry and Molecular Biology, Institute of Basic Medical Sciences, CAMS \& PUMC, Beijing 100005, China
}

range inhibit tumor formation by acting on antioxidants and in the inhibition of DNA adduct formation, the promotion of cell cycle progression and DNA repair [14-16]. However, super-nutritional levels of selenite induce endoplasmic reticulum stress, mitochondrial-related apoptosis, DNA strand breaks and cell-cycle arrest [15-19]. Therefore, many molecules, such as Akt, GADD153, P53, ERK, P38, Bad, Bim and Bax [20-24], have been reported to be involved in high-dose selenite-induced apoptosis. Additionally, super-nutritional selenite intake has been shown to be toxic to drug-resistant cancer cells and effective on tumor xenografts, which suggests that selenite has potential therapeutic effects [23-25].

In an in-depth study of selenium, selenite was reported to have strong inhibitory effects on sulfhydryl-containing proteins [15] such as tubulins, which composed microtubules $[26,27]$, but the effects of selenite on microtubules

\section{Biomed Central}


in cancer cells had not been proven. Based on our proteomics study, proteins linked to microtubule dynamics were thought to have roles in selenite-triggered apoptosis [28]. Therefore, our study aimed to investigate the role of selenite in microtubule assembly and induction of apoptosis.

\section{Results}

Sodium selenite inhibits growth and induces apoptosis in HL60 cells

We first observed that selenite inhibited growth of HL60 cells. After cells were exposed to differing concentrations of sodium selenite, cell viability was assessed using CCK-8 kits. Figure $1 \mathrm{~A}$ showed that $20 \mu \mathrm{M}$ selenite significantly reduced cell viability after $24 \mathrm{~h}$. To further investigate if growth inhibition was caused by apoptosis, the cells were stained with Annexin V-FITC/PI. Flow cytometry analysis proved that typical apoptosis was elicited by $20 \mu \mathrm{M}$ selenite (Figure 1B). To identify which pathway participated in selenite-induced apoptosis, we extracted the mitochondrial fraction of HL60 cells after they were exposed to selenite and discovered that cytochrome $\mathrm{C}$ and AIF were released (Figure 1C), which suggested that a mitochondrial-related apoptotic pathway was utilized. Furthermore, we observed nuclear fragmentation after staining with DAPI (Figure 1D).

\section{Sodium selenite alters microtubule assembly in cultured leukemia cells}

We then determined the mechanisms by which selenite inhibited the growth of HL60 cells. Tubulin exists in mainly two forms: soluble heterodimers that are composed of $\beta$ - and $\alpha$-tubulin or insoluble polymers. To detect whether selenite induced microtubule depolymerization, we extracted insoluble and soluble tubulin and discovered that $20 \mu \mathrm{M}$ selenite destroyed microtubules. Furthermore, we observed a significant decrease of insoluble tubulin,

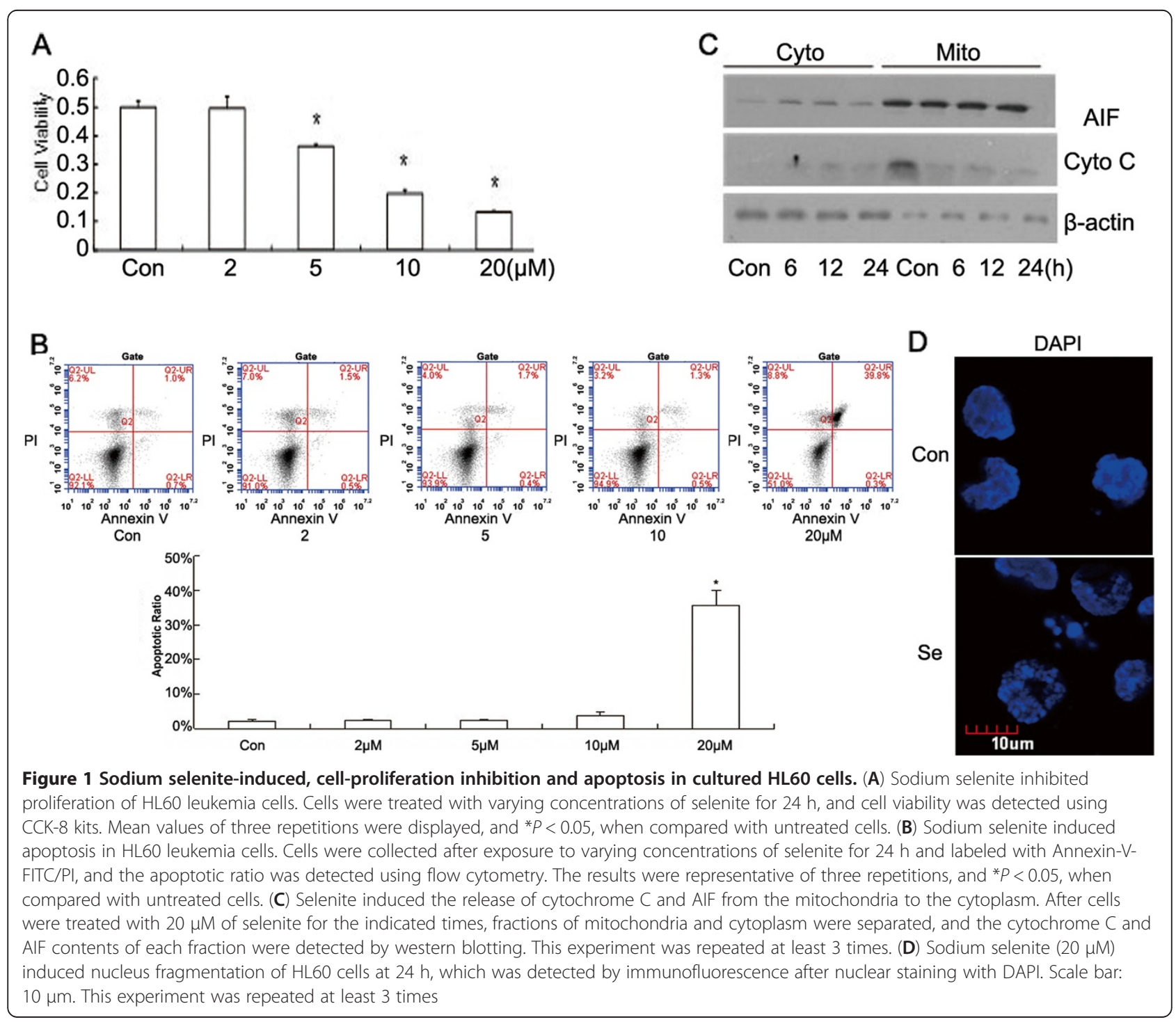


while Jurkat cells reassembled microtubules after $2 \mathrm{~h}$ of selenite exposure (Figure 2A). Indirect immunofluorescence showed that microtubules presented an integrated, filamentous structure in untreated cells but were dispersive in response to selenite in HL60 cells (Figure 2B).

\section{Sodium selenite-treated HL60 cells are arrested at G2/M phase}

We aimed to determine if crosstalk between microtubule disruption and the mitochondrial apoptotic pathway occurred. Because cell cycle arrest could be induced by microtubule disruption and some cell cycle-related protein kinases could regulate proteins in the mitochondria, we analyzed alterations in the cell cycle distribution of HL60 cells after selenite treatment. Compared with control, the number of cells was lower at G0/G1 phase and higher at G2/M phase after selenite treated for $24 \mathrm{~h}$ (Figure 3A). In addition, the protein level of Cyclin B1, a G2/M phase marker, was remarkably increased. This was concomitant with a decrease in Mcl-1, which was located in the mitochondria, in a time-dependent manner (Figure 3B). To illuminate the effect of microtubule disruption on cell cycle arrest, we employed a combined treatment of sodium selenite and Taxol (microtubule stabilizer) in HL60 cells and observed that the alteration of Cyclin B1 was abrogated (Figure 3C). As mentioned above, microtubule reorganization occurred in Jurkat cells; therefore, we destroyed microtubule reassembly through a combination of selenite and Colchicine treatments (microtubule depolymerization agent) and found that the alterations in Mcl-1 and Cyclin B1 levels were similar to those in selenite-treated HL60 cells (Figure 3D).

\section{Cyclin B1 interacted with CDK1 and induced down- regulation of $\mathrm{Mcl}-1$}

All of the above-described observations demonstrated that microtubule depolymerization was induced by selenite and took part in the inhibition of HL60 cell cycle progression. Because Cyclin B1 is necessary in G2/M phase for the activity of CDK1, which phosphorylates and destabilizes Mcl-1, we confirmed the cellular interactions between CDK1, Cyclin B1 and Mcl-1 (Figure 4A). Furthermore, either inhibition of Cyclin B1 expression by siRNA interference or inhibition of CDK1/Cyclin B1 activity by Roscovitine rescued the down-regulation of $\mathrm{Mcl}-1$ (Figure 4B,C). To further identify the protective role of Mcl-1, which was consistently altered upon cell cycle arrest, we down-regulated Mcl-1 by siRNA interference and observed HL60 cell death by cell counting using the CCK8 kits (Figure 4D, E). Additionally, silencing Mcl-1 after

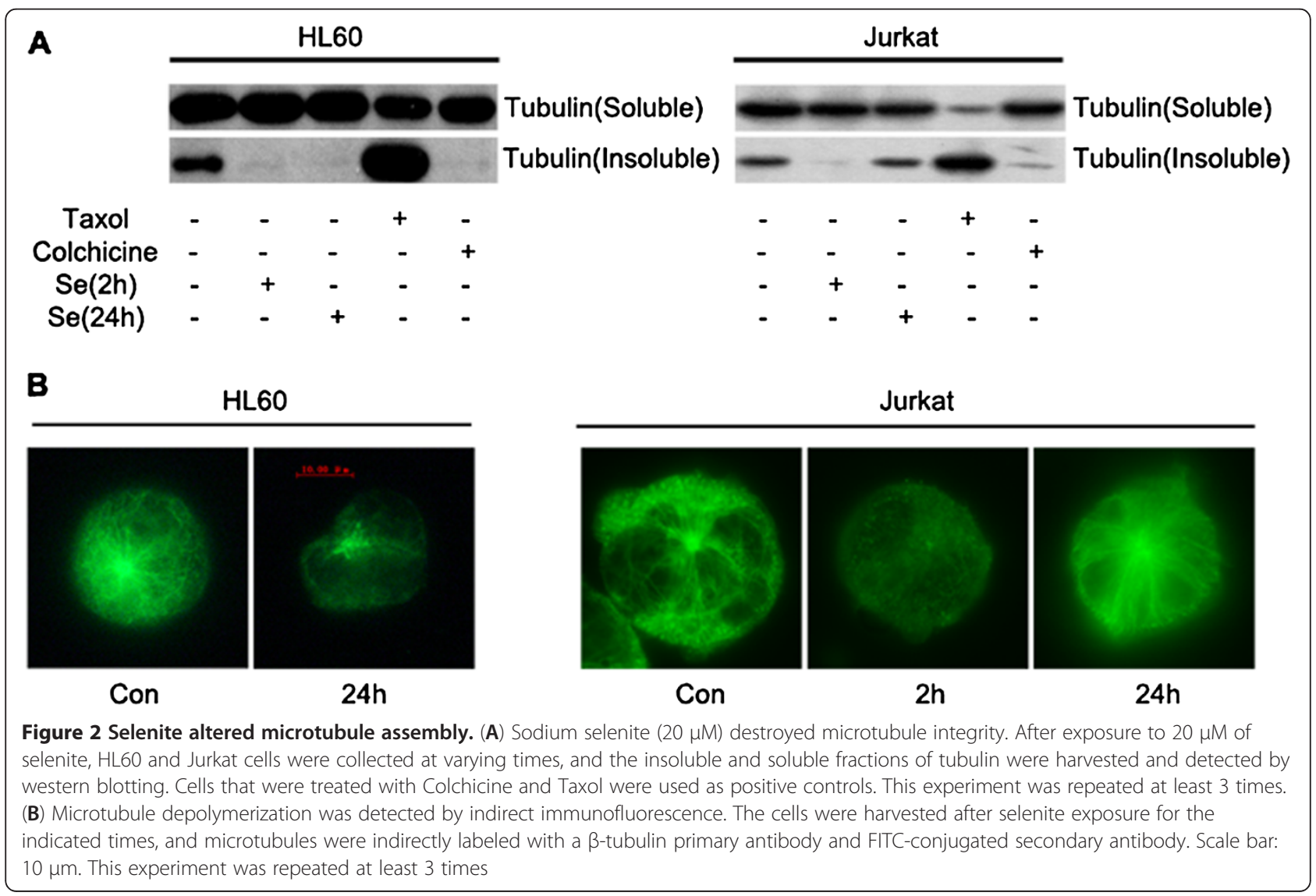




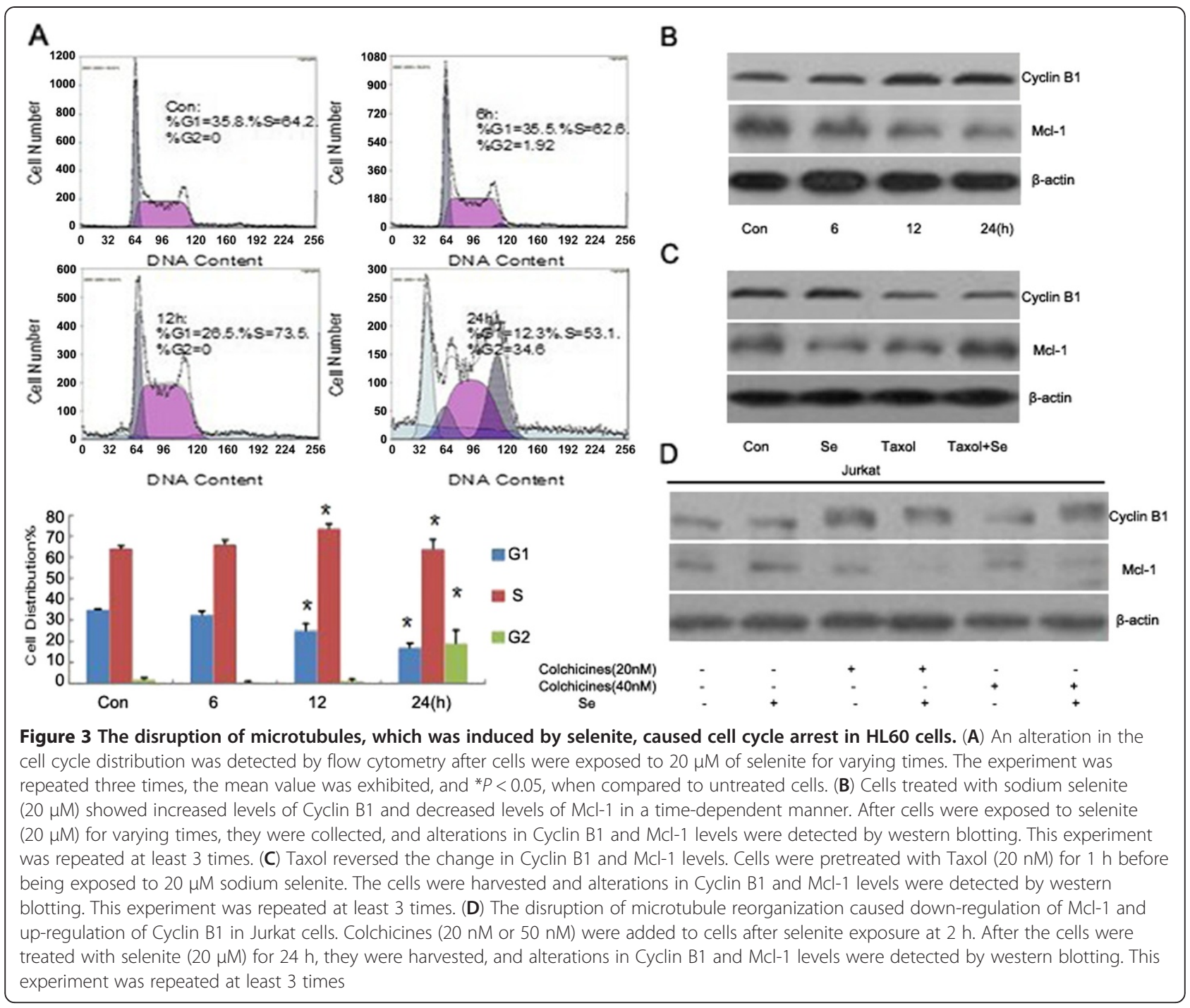

selenite exposure increased the apoptotic ratio of HL60 cells (Figure 4F).

\section{Selenite exhibits inhibitory effects on HL60 tumor xenografts}

Finally, we determined the effects of selenite $(1.5 \mathrm{mg} / \mathrm{kg} /$ day) on HL60 tumor xenografts. When compared with the control group, the volume and weight of the tumor and spleen were reduced in mice exposed to selenite (Figure 5A, C). Spleen enlargement could be caused by the infiltration of leukemic cells and it reflected the malignant degree of tumor cells. CD33 is a known marker of leukemic cells. Therefore, we detected CD33-positive cells in the spleen tissue and discovered that CD-33 positive cells decreased after selenite treatment, which also suggested that selenite had antitumor activity (Figure 5D). In addition, HE staining result indicated that selenite caused nucleus pyknosis (Figure 5B). Furthermore, in situ detection of apoptotic tumor cells by the TUNEL assay showed that there were more apoptotic cells after selenite treatment (Figure 5G). These results suggested that selenite had therapeutic effects on HL60 xenografts. To determine whether microtubules were depolymerized in this model, we separated soluble and insoluble tubulin and found that the amount of insoluble tubulin was decreased (Figure 5E). Furthermore, results in Figure $5 \mathrm{~F}$ showed that selenite up-regulated Cyclin B1 and down-regulated Mcl-1 levels, which was consistent with the in vitro findings. Immunohistochemical staining also indicated that Cyclin B1 and Mcl-1 levels were altered similarly to those in vitro (Figure $5 \mathrm{H}$ ).

\section{Discussion}

Selenium is an essential trace element for animals, and it has been shown that super-nutritional selenite intake has anti-tumor activity $[14,18,19,27,29]$. Several reports have also proved the anti-tumor effects of selenite in vivo [24]. However, the effects of selenite on 


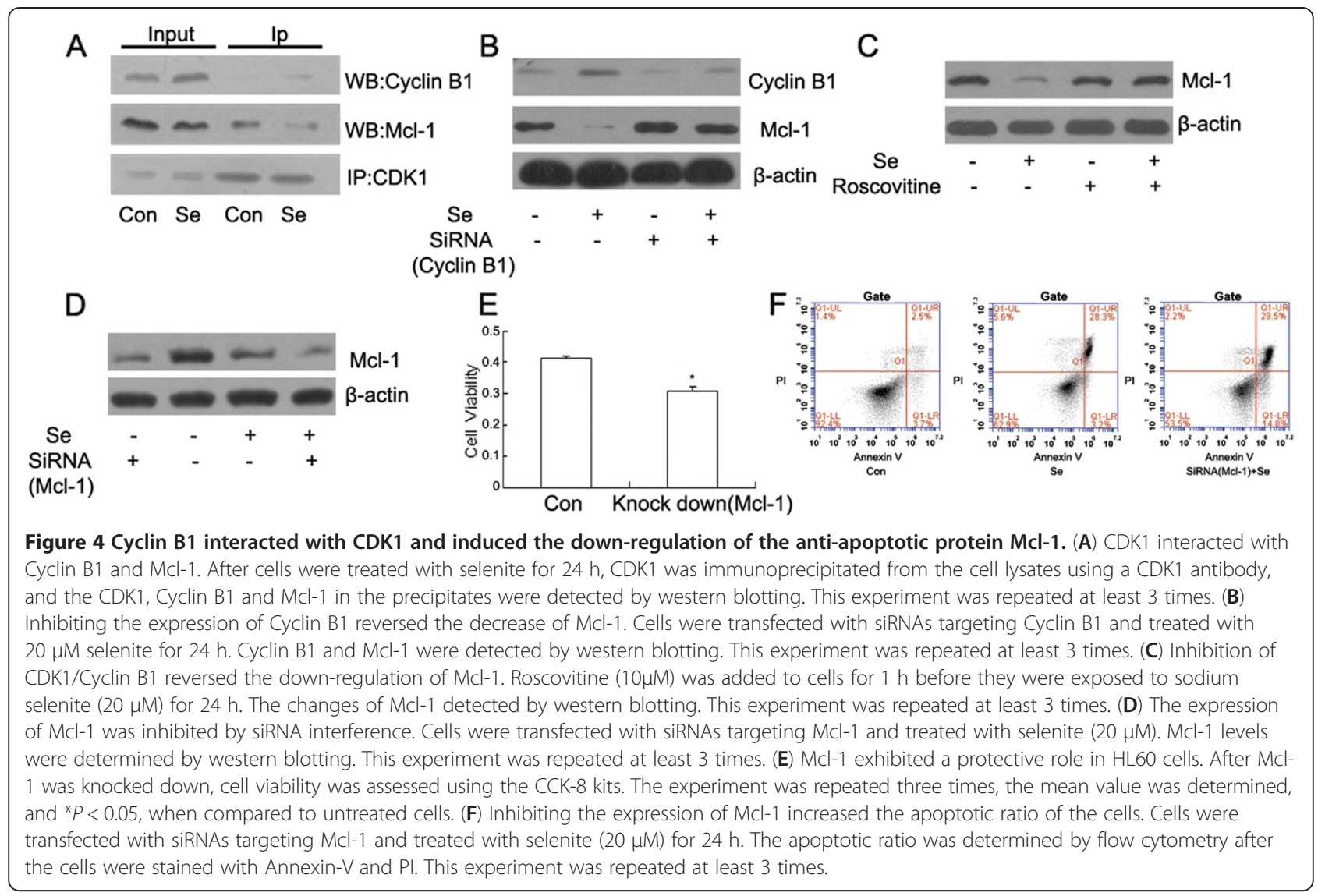

microtubule dynamics in cancer cells have not been demonstrated. Our study indicated that microtubules were a novel target of selenite.

Leynadier D et al. first discovered that selenite could directly interact with the sulfhydryl groups of $\beta$-tubulin and could inhibit microtubule polymerization in vitro [26]. To our knowledge, we are the first to discover that selenite also induces microtubule depolymerization in HL60 cells and in vivo. However, because microtubules reorganized in Jurkat but not in HL60 cells, the apoptotic mechanisms of the two cell lines differed. We mainly investigated the mechanisms by which selenite induced apoptosis. Because tumor cells have a strong ability to replicate themselves and tubulins, which compose spindles, are essential for this process, we speculate that selenite-induced apoptosis is at least partly dependent on the effects of selenite on microtubules. Therefore, the growth inhibitory effect of selenite on cultured HL60 cells was assessed, and we discovered that $20 \mu \mathrm{M}$ of sodium selenite significantly inhibited cell growth. Furthermore, Annexin V-FITC/PI double staining assay proved that selenite-induced apoptosis occurred and nuclear fragmentation was witnessed in selenite-treated cells. Last, we discovered that cytochrome $\mathrm{C}$ and AIF were released from the mitochondria to the cytoplasm, which suggested that selenite-induced apoptosis in HL60 cells might be associated with the mitochondrial apoptotic pathway. Cell cycle-related proteins that were consistently altered with microtubule dynamics could regulate Bcl-2 family members, which were located in the mitochondria. Therefore, we speculated that selenite inhibited HL60 cell growth through its effects on microtubules.

Several reports suggested that microtubule-interfering drugs affected cell cycle distribution by regulating the activity of CDKs and, therefore, altering protein phosphorylation at different cell cycle phases [11]. Mcl-1, a Bcl-2 family member, is regulated by the Cyclin B1/ CDK1 complex and is linked to the mitochondrial apoptotic pathway by binding and inhibiting pro-apoptotic proteins $[12,30,31]$. Our current study proved that selenite could induce cell cycle arrest and remarkable alterations of Cyclin B1 and Mcl-1 levels in HL60 cells through its effect on microtubule depolymerization. Interestingly, a combination treatment of Colchicine and selenite in Jurkat cells up-regulated Cyclin B1 and down-regulated Mcl-1. The observations in Jurkat cells also supported the relationship between microtubule destruction and alterations in Cyclin B1 and Mcl-1 after selenite exposure. Cyclin B1 is necessary for the activity 


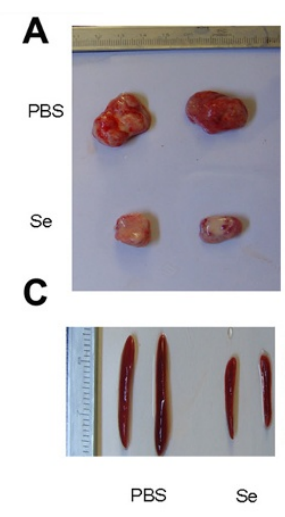

E
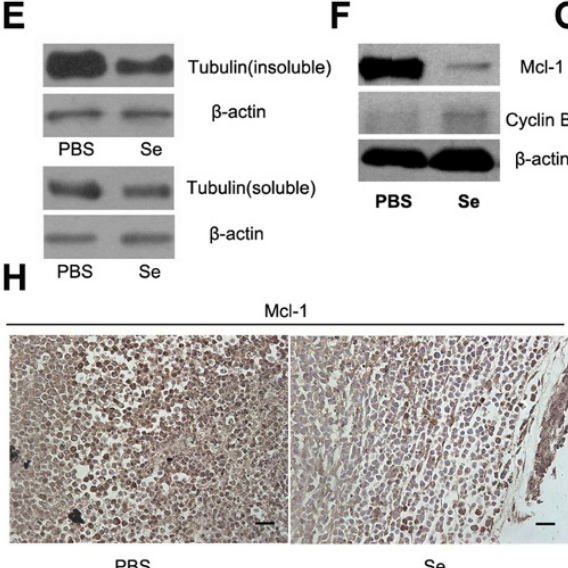

G

$\mathbf{F}$

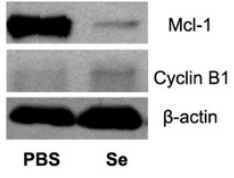

B

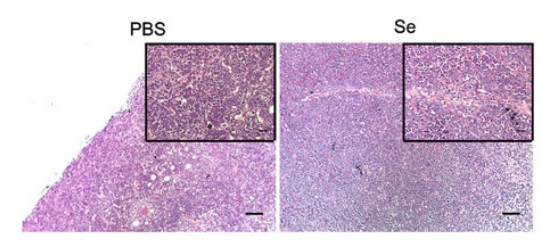

D
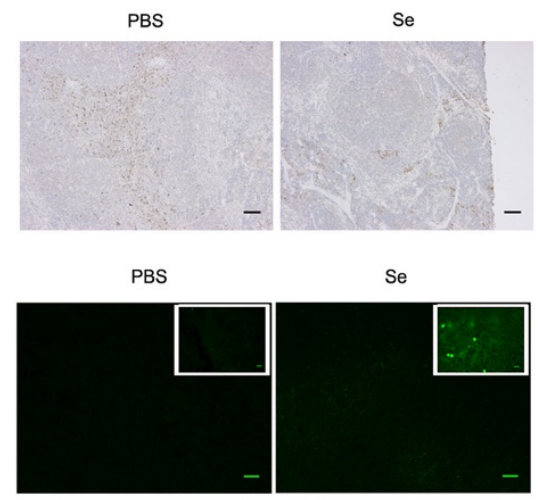

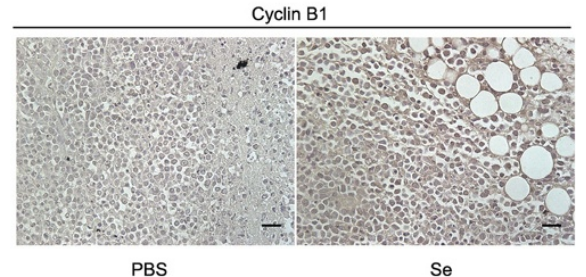

PBS

Se

Figure 5 Selenite had inhibitory effects on a HL60 xenograft tumor model. 4-week-old mice were divided into two groups randomly and each group was marked and put into its own box. The two groups lived in the same context and were fed with the same food and water. Then HL60 cells were given subcutaneously. After 1 week and tumors were detectable, PBS and selenite $1.5 \mathrm{mg} / \mathrm{kg} /$ day) were given to the control and selenite-treated group every two days respectively. After each group was injected for 3 weeks, nude mice were sacrificed for analysis. (A) Tumor weight decreased after selenite exposure. ${ }^{*} P<0.05$. (B) Selenite caused nuclear pyknosis in tumor cells. This experiment was repeated at least 3 times. (C) Spleen weight decreased after selenite exposure. ${ }^{*} P<0.05$. (D) Immunohistochemical staining indicated CD33 positive leukemia cells in spleen were decreased after selenite treated. Scale bar represented $100 \mu \mathrm{m}$. This experiment was repeated at least 3 times. (E) Selenite induced microtubule depolymerization in tumor cells. Soluble and insoluble-tubulin fractions were separated as indicated above and detected by western blotting. This experiment was repeated at least 3 times. (F) Selenite had similar effects on the regulation of Cyclin B1 and Mcl-1 as it did in vitro. This experiment was repeated at least 3 times. (G) In situ labeling of apoptotic tumor cells using the TUNEL assay indicated the appearance of apoptotic cells after selenite treatment. Scale bar represented $100 \mu \mathrm{m}$. This experiment was repeated at least 3 times. $(\mathbf{H})$ Immunohistochemical staining indicated that alterations in Cyclin B1 and Mcl-1 levels were similar to those in vitro. Scale bar represented $25 \mu \mathrm{m}$. This experiment was repeated at least 3 times

of CDK1, which phosphorylates and destabilizes Mcl-1 [32-36]. We observed that Cyclin B1 interacted with CDK1. Furthermore, either siRNA interference of Cyclin $\mathrm{B} 1$ or inhibition of the CDK1/Cyclin B1 complex with Roscovitine rescued the decrease of Mcl-1. Further investigation confirmed the protective role of Mcl-1 on HL60 cells and suggested that the growth inhibitory effects of selenite might be associated with the downregulation of Mcl-1. Finally, a combination of siRNA targeting Mcl-1 and selenite treatment caused a higher apoptotic ratio than selenite treatment alone. These results supported our conclusion that selenite altered microtubule assembly and inhibited HL60 cell growth through cell cycle arrest and decrease in Mcl-1 levels.

The above-described experiments indicated that selenite altered microtubule assembly and induced cell cycle arrest in HL60 cells. To identify the therapeutic activity of selenite in vivo, we established a HL60-cell-bearing nude mice model. Experiments in vivo showed that selenite inhibited tumor growth and induced nucleus pyknosis. Furthermore, we also found that selenite depolymerized microtubules in vivo. Additional experiments demonstrated that alterations of Cyclin B1 and Mcl-1 levels in the nude mice model were similar to those 
findings in vitro, which suggested that the mechanisms demonstrated in vitro were also active at the tissue level.

\section{Conclusions}

In conclusion, the microtubule destruction that was induced by selenite stimulated the apoptotic pathway by up-regulating Cyclin B1, which interacted with CDK1 and destabilized the anti-apoptotic protein Mcl-1. We also found that sodium selenite had therapeutic functions in a HL60-cell-bearing nude mice model through its microtubule destruction effects. Importantly, this investigation explored the effects of selenite on apoptosis in a distinct way.

\section{Materials and methods}

\section{Chemicals and antibodies}

Roscovitin, anti- $\beta$-Tubulin (2-28-33) and anti- $\beta$-Actin (AC-15) antibodies were obtained from Sigma-Aldrich. Anti-Cyclin B1 and anti-Mcl-1 antibodies, which were used for western blotting, were obtained from Cell Signaling Technology. For immunohistochemical staining, an anti-Cyclin B1 antibody was purchased from Excell, an-anti CD33 antibody was purchased from BIOSS and an anti-Mcl-1 antibody was purchased from Santa Cruz. The Cdc2 (1/Cdk1/Cdc2) antibody was purchased from BD Biosciences Pharmingen. HRP-conjugated anti-mouse and anti-rabbit antibodies were purchased from ZSGBBIO. A FITC-conjugated anti-mouse antibody was purchased from Jackson.

\section{Cell culture}

HL60 and Jurkat cells were grown in RPMI 1640 medium containing $10 \%$ advanced fetal bovine serum, 100 units $/ \mathrm{mL}$ penicillin and 100 units $/ \mathrm{mL}$ streptomycin and incubated in a humidified, $5 \% \mathrm{CO}_{2}$ incubator that was set at $37^{\circ} \mathrm{C}$.

\section{Indirect immunofluorescence microscopy}

HL60 cells $\left(8 \times 10^{5}\right.$ total $)$ were harvested. The cells were transferred to slides, fixed in $4 \%$ paraformaldehyde and permeabilized using $0.1 \%$ Triton X-100. After the slides were blocked with $2 \%$ BSA, the cells were incubated with $\beta$-tubulin antibody overnight at $4^{\circ} \mathrm{C}$. After washing with PBS three times, the cells were incubated with FITC-conjugated secondary antibody for $60 \mathrm{~min}$ at room temperature. After a second round of washing, the cells were stained with DAPI for approximately $5 \mathrm{~min}$, and the slides were washed three times and mounted in antifading medium. Images were visualized using a Zeiss microscope (Carl Zeiss, Jena, Germany).

\section{Western blotting}

Approximately $1 \times 10^{6}$ cells were collected for each treatment. After washing with ice-cold PBS, the cells were resuspended in RIPA lysis buffer (20 nM Tris, $\mathrm{pH}$ 7.5; 1 mM EDTA; 1 mM EGTA; $150 \mathrm{mM} \mathrm{NaCl}$; $1 \%$ Triton X-100; $2.5 \mathrm{mM}$ sodium pyrophosphate; $1 \mathrm{mM} \beta$ glycerolphosphate; $1 \mathrm{mM} \mathrm{Na} \mathrm{VO}_{4} ; 1 \mathrm{mM}$ PMSF; and $1 \mu \mathrm{g} / \mathrm{mL}$ leupeptin) and were submitted to ultrasonication on ice. The lysates were centrifuged at $12,000 \times g$ for $20 \mathrm{~min}$ at $4^{\circ} \mathrm{C}$, and equal amounts of proteins were separated by SDS-PAGE. The proteins on the PAGE gel were then transferred to a nitrocellulose membrane. After being blocked with 5\% non-fat milk, the membranes were washed with TBST and incubated overnight with primary antibody at $4^{\circ} \mathrm{C}$. After being washed three times with TBST, the membranes were incubated with a HRP-conjugated secondary antibody for approximately $1 \mathrm{~h}$ at room temperature. Subsequently, the membranes were washed another three times and probed with supersignal chemiluminescent substrate.

\section{Immunoprecipitation}

Cells $\left(1 \times 10^{7}\right)$ were harvested and washed twice with ice-cold PBS. The pellets were resuspended in RIPA buffer and lysed on ice for $30 \mathrm{~min}$. Subsequently, the lysates were centrifuged at $12,000 \times g$ for $20 \mathrm{~min}$ at $4^{\circ} \mathrm{C}$. A suitable amount of cdc2 antibody was added to the protein lysate $(200 \mu \mathrm{g})$ and rotated overnight at $4^{\circ} \mathrm{C}$, while the remaining protein was used as input. Protein $A+G$ was added, and the mixture was rotated for another $3 \mathrm{~h}$ at $4^{\circ} \mathrm{C}$; then, the samples were washed with RIPA buffer three times. Finally, the beads were resuspended in $3 \times$ SDS loading buffer and boiled for $10 \mathrm{~min}$. After a short centrifugation step, the supernatant was collected.

\section{siRNA interference}

siRNAs targeting Cyclin B1 (5'-CCAAACCTTTGTAGT GAAT-3'), Mcl-1 (5'-GGACTGGCTAGTTAAACAA-3') and negative controls for each sequence were synthesized by GenePharma. Approximately $1 \times 10^{7}$ cells were collected and washed with Opti-MEM medium (Gibco). Then, the cells were transfected with $200 \mathrm{nM}$ siRNA and RNAiMAX in Opti-MEM. After transfection for approximately $12 \mathrm{~h}$, the cells were treated with sodium selenite for $24 \mathrm{~h}$.

\section{Detection of cell cycle distribution}

Approximately $1 \times 10^{6}$ cells were collected and fixed in $70 \%$ ethanol overnight at $4^{\circ} \mathrm{C}$. Each sample was centrifuged at $1,000 \times g$ for $10 \mathrm{~min}$ at room temperature and washed with ice-cold PBS. Subsequently, the cells were incubated with $50 \mu \mathrm{g} / \mathrm{ml}$ RNase in PBS for $30 \mathrm{~min}$ at $37^{\circ} \mathrm{C}$. After adding PI to the cells at a final concentration of $50 \mu \mathrm{g} / \mathrm{mL}$, we detected the absorption at $620 \mathrm{~nm}$ by flow cytometry. 


\section{Detection of apoptosis with AnnexinV-FITC/PI staining}

The cells $\left(1 \times 10^{6}\right)$ were harvested and washed twice with ice-cold PBS. Subsequently, the cells were stained with AnnexinV-FITC in binding buffer in the dark for $15 \mathrm{~min}$. After being centrifuged at $1,000 \times g$ for $10 \mathrm{~min}$, the cells were resuspended in binding buffer containing PI. Finally, the apoptotic ratio was determined by an Accuri C6 flow cytometry. We calculated the apoptotic ratio by calculating the sum of Annexin $\mathrm{V}^{+} / \mathrm{PI}^{-}$cells' ratio and Annexin $\mathrm{V}^{+} / \mathrm{PI}^{+}$cells' ratio.

\section{The effect of sodium selenite on the viability of HL60 cells}

HL60 cells were seeded into a 96-well plate at a concentration of 40,000 cells per well. After treatment with varying concentrations of sodium selenite for $24 \mathrm{~h}$, cell viability was assessed using CCK-8 kits (Dojindo Molecular Technologies, Tokyo, Japan).

\section{The in vivo microtubule polymerization assay}

An established method was modified and used to separate insoluble tubulin from soluble tubulin [30]. Approximately $2 \times 10^{6}$ cells were collected and washed twice. The cells were then resuspended in hypotonic buffer at $37^{\circ} \mathrm{C}$ for $5 \mathrm{~min}$. After centrifugation at $14,000 \times g$ for $10 \mathrm{~min}$ at $25^{\circ} \mathrm{C}$, the supernatants, which contained soluble tubulin, were collected, and the pellets containing insoluble tubulin were resuspended in RIPA buffer and subjected to ultrasonication on ice. The lysates were centrifuged at $12,000 \times g$ for $10 \mathrm{~min}$ at $4^{\circ} \mathrm{C}$, and the supernatants were collected.

\section{Xenograft tumor model}

At the beginning of the experiment, 4-week-old female mice were chosen and divided into control or selenitetreated group randomly. Each group was marked and put into its own box. The two groups lived in the same context and were fed with the same food and water. Leukemia HL60 cells were inoculated subcutaneously into female nude mice. After tumors were palpable, an intraperitoneal injection of sodium selenite dissolved in PBS was given to each mouse every 2 days $(1.5 \mathrm{mg} / \mathrm{kg} /$ day) for 3 weeks, and the control group was treated with PBS for the same period time. At the end of the experiment, the mice were sacrificed, and the tumors and spleens were rapidly removed and weighed. The Declaration of Helsinki and the guide for Laboratory Animal Care and Use were maintained.

\section{Immunohistochemical staining}

The slides were deparaffinized in xylene and dehydrated with decreasing concentrations of ethanol. After the slides were washed with running water for $2 \mathrm{~min}$, endogenous peroxidase was blocked with $3 \%$ peroxide that was dissolved in methanol. Subsequently, the slides were immersed in boiled sodium citrate for antigen retrieval, and after being washed three times with $0.01 \mathrm{M}$ PBS for $5 \mathrm{~min}$, the slides were incubated with either anti-Mcl-1 or anti-Cyclin B1 antibody overnight at $4^{\circ} \mathrm{C}$. The slides were incubated with secondary antibody at room temperature for $3 \mathrm{~h}$, treated with $\mathrm{DAB}$, stained with Mayer's hematoxylin for 2 min and washed with running water. Slides were then dehydrated with increasing concentrations of ethanol and clarified with xylene. Finally, the slides were mounted with medium.

\section{HE staining}

After dehydration with decreasing concentrations of ethanol as described above, the slides were stained with Harriss hematoxylin for $15 \mathrm{~min}$ and washed for $3 \mathrm{~min}$. Then, the slides were immersed in $1 \%$ hydrochloric acid dissolved in $75 \%$ ethanol for $30 \mathrm{~s}$. Before dehydration, the slides were stained with eosin for $10 \mathrm{~min}$. Finally, the slides were clarified with xylene and mounted with medium.

\section{TUNEL assay}

A FragEL ${ }^{\mathrm{T} M}$ DNA Fragmentation Detection Kit was purchased from MERCK. The slides were deparaffinized in xylene and dehydrated with decreasing concentrations of ethanol. After washing with $1 \times$ TBS for $2 \mathrm{~min}$, the slides were incubated with $20 \mu \mathrm{g} / \mathrm{ml}$ proteinase $\mathrm{K}$ for $20 \mathrm{~min}$ at room temperature. The slides were then washed with $1 \times$ TBS and incubated with $1 \times$ TdT buffer for approximately $30 \mathrm{~min}$ at room temperature. Subsequently, the slides were incubated with $57 \mu \mathrm{l}$ of mix buffer and $3 \mu \mathrm{l}$ of TdT enzyme for $60 \mathrm{~min}$ at $37^{\circ} \mathrm{C}$. After being washed three times with $1 \times \mathrm{TBS}$, the slides were mounted with medium.

\section{Statistical analysis}

The values were represented as mean \pm SEM. Two-tailed students' t-tests were used for two groups comparison analysis, and $\mathrm{P}<0.05$ was considered to be significant. The bar charts were used to reflect the alterations of experimental data $[18,24,37,38]$.

\section{Competing interests}

The authors declare that they have no competing interests.

\section{Authors' contributions}

KS designed and finished most of the project, and drafted the manuscript. QJ and ZL helped KS design the project. QJ, LS and FL helped KS establish the HL60 cells bearing nude mice model. Indirect immunofluorescence staining was performed by JA. Statistical analysis was performed by YY. CX is the supervisor of all authors and provides some helps in manuscript editing and project design. All authors read and approved the final manuscript.

Authors' information

First author: Kejian Shi. 


\section{Acknowledgements}

First of all, we would like to specially thank Dr. Yun Shen, Dr. Qun Xu and Master Yang Yang for their selfless aids. This work was supported by the National Natural Science Foundation of China (No. 31170788 and No. 30970655), the National Natural Science Foundation for Young Scholars of China (No. 31101018), the Natural Science Foundation of Beijing (No. 5082015), the State Key Laboratory Special Fund (No. 2060204) and the Ministry of Education of China Doctor Training Unit (No. 20091106110025).

Received: 19 November 2012 Accepted: 9 January 2013

Published: 17 January 2013

\section{References}

1. Downing KH: Structural basis for the interaction of tubulin with proteins and drugs that affect microtubule dynamics. Annu Rev Cell Dev Biol 2000 16:89-111.

2. Nogales E, Wang HW: Structural intermediates in microtubule assembly and disassembly: how and why? Curr Opin Cell Biol 2006, 18:179-184

3. McIntosh JR, Hering GE: Spindle fiber action and chromosome movement. Annu Rev Cell Biol 1991, 7:403-426

4. Walker RA, O'Brien ET, Pryer NK, Soboeiro MF, Voter WA, Erickson HP, Salmon ED: Dynamic instability of individual microtubules analyzed by video light microscopy: rate constants and transition frequencies. J Cell Biol 1988, 107:1437-1448.

5. Carlier MF: Role of nucleotide hydrolysis in the dynamics of actin filaments and microtubules. Int Rev Cytol 1989, 115:139-170.

6. Erickson HP, O'Brien ET: Microtubule dynamic instability and GTP hydrolysis. Annu Rev Biophys Biomol Struct 1992, 21:145-166.

7. Meshkini A, Yazdanparast R: Involvement of oxidative stress in taxolinduced apoptosis in chronic myelogenous leukemia K562 cells. Exp Toxicol Pathol 2012, 64:357-365.

8. Wilson L, Jordan MA: Microtubule dynamics: taking aim at a moving target. Chem Biol 1995, 2:569-573.

9. Hamel E, Lin CM: Reexamination of the role of nonhydrolyzable guanosine 5/-triphosphate analogues in tubulin polymerization: reaction conditions are a critical factor for effective interactions at the exchangeable nucleotide site. Biochemistry 1990, 29:2720-2729.

10. Tanaka E, Ho T, Kirschner MW: The role of microtubule dynamics in growth cone motility and axonal growth. J Cell Biol 1995, 128:139-155.

11. Pietenpol JA, Stewart ZA: Cell cycle checkpoint signaling: cell cycle arrest versus apoptosis. Toxicology 2002, 181-182:475-481.

12. Bhalla KN: Microtubule-targeted anticancer agents and apoptosis. Oncogene 2003, 22:9075-9086.

13. Behne D, Kyriakopoulos A: Mammalian selenium-containing proteins. Annu Rev Nutr 2001, 21:453-473.

14. Guan L, Han B, Li J, Li Z, Huang F, Yang Y, Xu C: Exposure of human leukemia NB4 cells to increasing concentrations of selenite switches the signaling from pro-survival to pro-apoptosis. Ann Hematol 2009, 88:733-742.

15. Brozmanova J, Manikova D, Vlckova V, Chovanec M: Selenium: a doubleedged sword for defense and offence in cancer. Arch Toxicol 2010, 84:919-938.

16. Zeng $\mathrm{H}$ : Selenite and selenomethionine promote $\mathrm{HL}-60$ cell cycle progression. J Nutr 2002, 132:674-679.

17. Cao TM, Hua FY, Xu CM, Han BS, Dong H, Zuo L, Wang X, Yang Y, Pan HZ, Zhang ZN: Distinct effects of different concentrations of sodium selenite on apoptosis, cell cycle, and gene expression profile in acute promyeloytic leukemia-derived NB4 cells. Ann Hematol 2006, 85:434-442.

18. Li Z, Shi K, Guan L, Cao T, Jiang Q, Yang Y, Xu C: ROS leads to MnSOD upregulation through ERK2 translocation and p53 activation in seleniteinduced apoptosis of NB4 cells. FEBS Lett 2010, 584:2291-2297.

19. Guan L, Han B, Li Z, Hua F, Huang F, Wei W, Yang Y, Xu C: Sodium selenite induces apoptosis by ROS-mediated endoplasmic reticulum stress and mitochondrial dysfunction in human acute promyelocytic leukemia NB4 cells. Apoptosis 2009, 14:218-225.

20. Han B, Wei W, Hua F, Cao T, Dong H, Yang T, Yang Y, Pan H, Xu C: Requirement for ERK activity in sodium selenite-induced apoptosis of acute promyelocytic leukemia-derived NB4 cells. J Biochem Mol Biol 2007, 40:196-204.
21. Zou Y, Niu P, Yang J, Yuan J, Wu T, Chen X: The JNK signaling pathway is involved in sodium-selenite-induced apoptosis mediated by reactive oxygen in HepG2 cells. Cancer Biol Ther 2008, 7:689-696.

22. Ren Y, Huang F, Liu Y, Yang Y, Jiang Q, X C: Autophagy inhibition through PI3K/Akt increases apoptosis by sodium selenite in NB4 cells. BMB Rep 2009, 42:599-604.

23. Yang $Y$, Huang $F$, Ren $Y$, Xing L, Wu Y, Li Z, Pan H, Xu C: The anticancer effects of sodium selenite and selenomethionine on human colorectal carcinoma cell lines in nude mice. Oncol Res 2009, 18:1-8.

24. Huang F, Nie C, Yang $Y$, Yue W, Ren Y, Shang Y, Wang X, Jin H, Xu C, Chen $\mathrm{Q}$ : Selenite induces redox-dependent Bax activation and apoptosis in colorectal cancer cells. Free Radic Biol Med 2009, 46:1186-1196.

25. Hu H, Jiang C, Schuster T, Li GX, Daniel PT, Lu J: Inorganic selenium sensitizes prostate cancer cells to TRAIL-induced apoptosis through superoxide/p53/Bax-mediated activation of mitochondrial pathway. Mol Cancer Ther 2006, 5:1873-1882.

26. Leynadier D, Peyrot V, Codaccioni F, Briand C: Selenium: inhibition of microtubule formation and interaction with tubulin. Chem Biol Interact 1991, 79:91-102.

27. Mi L, Xiao Z, Hood BL, Dakshanamurthy S, Wang X, Govind S, Conrads TP, Veenstra TD, Chung FL: Covalent binding to tubulin by isothiocyanates. A mechanism of cell growth arrest and apoptosis. J Biol Chem 2008, 283:22136-22146.

28. Dong H, Ying T, Li T, Cao T, Wang J, Yuan J, Feng E, Han B, Hua F, Yang Y, et al: Comparative proteomic analysis of apoptosis induced by sodium selenite in human acute promyelocytic leukemia NB4 cells. J Cell Biochem 2006, 98:1495-1506.

29. Jiang $Q$, Wang Y, Li T, Shi K, Li Z, Ma Y, Li F, Luo H, Yang Y, Xu C: Heat shock protein 90-mediated inactivation of nuclear factor-kappaB switches autophagy to apoptosis through becn 1 transcriptional inhibition in selenite-induced NB4 cells. Mol Biol Cell 2011, 22:1167-1180

30. Yang JS, Hour MJ, Huang WW, Lin KL, Kuo SC, Chung JG: MJ-29 inhibits tubulin polymerization, induces mitotic arrest, and triggers apoptosis via cyclin-dependent kinase 1-mediated Bcl-2 phosphorylation in human leukemia U937 cells. J Pharmacol Exp Ther 2010, 334:477-488.

31. Wang YF, Jiang CC, Kiejda KA, Gillespie S, Zhang XD, Hersey P: Apoptosis induction in human melanoma cells by inhibition of MEK is caspaseindependent and mediated by the Bcl-2 family members PUMA, Bim, and Mcl-1. Clin Cancer Res 2007, 13:4934-4942.

32. Chen YC, Lu PH, Pan SL, Teng CM, Kuo SC, Lin TP, Ho YF, Huang YC, Guh $\mathrm{JH}$ : Quinolone analogue inhibits tubulin polymerization and induces apoptosis via Cdk1-involved signaling pathways. Biochem Pharmacol 2007, 74:10-19.

33. Doma E, Chakrabandhu K, Hueber AO: A novel role of microtubular cytoskeleton in the dynamics of caspase-dependent Fas/CD95 death receptor complexes during apoptosis. FEBS Lett 2010, 584:1033-1040.

34. Shin JW, Son JY, Kang JK, Han SH, Cho CK, Son CG: Trichosanthes kirilowii tuber extract induces G2/M phase arrest via inhibition of tubulin polymerization in HepG2 cells. J Ethnopharmacol 2008, 115:209-216.

35. Harley ME, Allan LA, Sanderson HS, Clarke PR: Phosphorylation of Mcl-1 by CDK1-cyclin B1 initiates its Cdc20-dependent destruction during mitotic arrest. EMBO J 2010, 29:2407-2420.

36. Mollinedo F, Gajate C: Microtubules, microtubule-interfering agents and apoptosis. Apoptosis 2003, 8:413-450.

37. Yedjou C, Tchounwou P, Jenkins J, McMurray R: Basic mechanisms of arsenic trioxide (ATO)-induced apoptosis in human leukemia (HL-60) cells. J Hematol Oncol 2010, 3:28.

38. Zou L, Zhang H, Du C, Liu X, Zhu S, Zhang W, Li Z, Gao C, Zhao X, Mei M, et al: Correlation of SRSF1 and PRMT1 expression with clinical status of pediatric acute lymphoblastic leukemia. J Hematol Oncol 2012, 5:42.

doi:10.1186/1756-8722-6-7

Cite this article as: Shi et al: Sodium selenite alters microtubule assembly and induces apoptosis in vitro and in vivo. Journal of Hematology \& Oncology 2013 6:7. 